\title{
Analysis of the morphology and composition of tooth apices apicectomized using three different ablation techniques
}

\author{
Ana-Cláudia Lustosa-Pereira ${ }^{1}$, Daniel-Humberto Pozza ${ }^{2}$, Alexandre Cunha ${ }^{3}$, Berenice-Anina Dedavid ${ }^{4}$, \\ João-Feliz Duarte-de Moraes ${ }^{5}$, Marília Gerhardt-de Oliveira ${ }^{6}$ \\ ${ }^{1} \mathrm{PhD}$, Professor, School of Dentistry, Universidade Paulista, Brasília, DF, Brazil \\ ${ }^{2} \mathrm{PhD}$, Researcher, Department of Histology and Embriology, School of Medicine, Universidade do Porto, Porto, Portugal \\ ${ }^{3} \mathrm{MSc}$, Researcher, Instituto Superior Técnico, Lisboa, Portugal \\ ${ }^{4} \mathrm{PhD}$, Professor, Engineering Department, Pontifícia Universidade Católica do Rio Grande do Sul, Porto Alegre, RS, Brazil \\ ${ }^{5} \mathrm{PhD}$, Professor, Mathematics Department, Pontifícia Universidade Católica do Rio Grande do Sul, Porto Alegre, RS, Brazil \\ ${ }^{6} \mathrm{PhD}$, Professor, School of Dentistry, Pontifícia Universidade Católica do Rio Grande do Sul PUCRS, Porto Alegre, RS, Brazil
}

Correspondence:

Rua Lucas de Oliveira, 1841/203

CEP 90460-001 - Porto Alegre, RS, Brazil

gerhardtoliveira@gmail.com

Received: 06/03/2010

Accepted: $31 / 05 / 2010$

\author{
Lustosa-Pereira AC, Pozza DH, Cunha A, Dedavid BA, Duarte-de Moraes \\ JF, Gerhardt-de Oliveira M. Analysis of the morphology and composition \\ of tooth apices apicectomized using three different ablation techniques. \\ Med Oral Patol Oral Cir Bucal. 2011 Mar 1;16 (2):e225-30. \\ http://www.medicinaoral.com/medoralfree01/v16i2/medoralv16i2p225.pdf

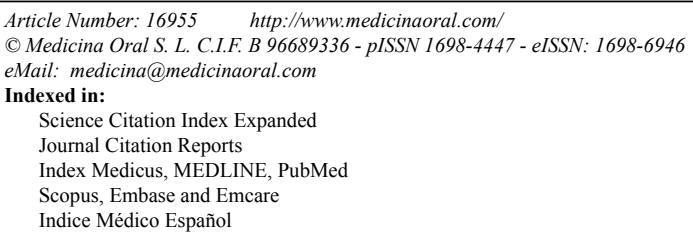

\begin{abstract}
Objectives: To investigate apicectomies performed using burs, a $\mathrm{CO}_{2}$ laser or an Er:YAG laser and to evaluate the following aspects: morphology of apicectomized surfaces, presence of failures at the dentin/obturation material interface (marginal fit) of the apical portions of the root canals, and the proportions of chemical elements in the apicectomized surfaces.

Study design: Twenty-four teeth were divided into three groups of eight and each group underwent apicectomy by one of three different ablation techniques: bur, $\mathrm{CO}_{2}$ laser or Er:YAG laser. The morphology of the apicectomized surfaces was then analyzed using scanning electron microscopy and their chemical composition was analyzed by energy dispersive spectroscopy.

Results: Surfaces produced with ablation by bur exhibited less surface irregularities and better marginal fit, while ablation with the $\mathrm{CO}_{2}$ laser caused intense surface carbonization and failures in obturation material fit.

Conclusions: Our results suggest that, taking into consideration their clinical application, ablation of tooth apices using burs proved to be the best option among those tested here.
\end{abstract}

Key words: Apicectomy, laser, scanning electron microscopy. 


\section{Introduction}

Root-end resection, also known as apicectomy, is a surgical procedure during which the apex of a root of a tooth is removed. It can be carried out using a variety of methods, the majority of which involve burs at fast or slow rotations (1). Recently, high-power lasers have been adopted as a technological resource for carrying out this procedure (2).

The advantages of laser irradiation in endodontics include elimination of the dentinal smear layer, opening of dentinal tubules and bactericidal action as a result of the laser-induced heat effect. Unfortunately, however, the temperature increment in the dentinal tissues can produce undesirable effects such as cracks or small fissures upon cooling (3).

Using a $\mathrm{CO}_{2}$ laser reduces dentinal permeability after irradiation and can induce the formation of secondary dentin (4). When used to treat hard tissues, $\mathrm{CO}_{2}$ laser can result in deleterious effects such as carbonization, melting and denaturing of proteins, resulting in the formation of toxic substances and changes to the composition of the irradiated tissues (5).

The wavelength of $2.94 \mu \mathrm{m}$ that Er:YAG lasers produce is readily absorbed by water. Er:YAG lasers can be used for a range of clinical dental treatments, for hard-tissue applications, such as apicectomies, for removing superficial calcium deposits and for removing cement from root apices. They also have bactericidal properties (6).

Er:YAG laser thermal ablation may cause dissolution of mineral components and fusion of amorphous particles without crystallization, resulting in a smoother and cleaner surface (1). The advantages of this type of laser compared to the burs are: better visibility, more accurate apical resection, absence of contact, faster removal due to vaporization, hemostasis, absence of vibration, very little pain, lower risk of trauma in the adjacent tissues (7).

Root surfaces irradiated with $\mathrm{CO}_{2}$ laser have craters presenting a carbonized superficial layer, forming a matrix similar to cementum and absence of dentin tubules (8). In addition, human teeth apicectomized using Er:YAG laser and $\mathrm{CO}_{2}$ laser compared to burs had smoother surfaces and more homogeneous fusion and recrystallization, with occluded tubules and reduced permeability (9).

The objective of this study was to investigate apicectomies performed using burs or laser technologies. The following aspects were evaluated after ablation of materials using burs, a $\mathrm{CO}_{2}$ laser or an Er:YAG laser: morphology of apicectomized surfaces and presence of failures at the dentin/obturation material interface (marginal fit) of the apical portions of the root canals, using scanning electron microscopy (SEM); and the proportions of chemical elements in the apicectomized surfaces, using energy dispersive spectroscopy (EDS).

\section{Materials and Methods}

The study employed 24 root apices from permanent human canine teeth (upper and lower), from patients with average age from 30 to 50 years.

\section{-Endodontic treatment}

The pulp content was removed from the root canals by means of chemical and mechanical preparation techniques. After complete removal of the pulp content, all of the root canals were irrigated with solutions of sodium chloride at $0.9 \%$ and ethylenediaminetetraacetic acid (EDTA) at 17\%, with the objective of removing the smear layer and the chemical substances used in the mechanical and chemical preparation process. After these cleaning procedures, the canals were dried using absorbent paper points and filled with obturation material consisting of gutta-percha cones covered in zinc oxide and eugenol endodontic sealer.

-Apicectomy of samples

The tooth apices were randomized into three groups of eight apices depending on the ablation technique, either mechanical or laser, and apicectomized $3 \mathrm{~mm}$ from the apical tip, maintaining an angle of $90^{\circ}$ to the axis of the root.

The samples in group A, used as a control group, were apicectomized using a conical diamond bur with a rounded tip (Ø ISO 18; $\mathrm{L}=11 \mathrm{~mm}$ ) at a rotation of $380,000 \mathrm{rpm}$ and under constant cooling with $0.9 \%$ $\mathrm{NaCl}$ solution.

The samples in group B were apicectomized with a $\mathrm{CO}_{2}$ laser (CW, 5W) without cooling, kept at a focal distance of approximately $12 \mathrm{~mm}$. No positioning devices were used to stabilize the distance between the laser beam and the apex with the objective of using a methodology similar to clinical practice and in order to allow ablation with the laser beam focused into the deepest areas.

The samples in group $\mathrm{C}$ were apicectomized using an Er:YAG laser (pulsed, $10 \mathrm{~Hz}, 400 \mathrm{~mJ}$ per pulse and 4 $\mathrm{W})$, under constant cooling with an air-water spray, with a focal distance varying between 8 and $10 \mathrm{~mm}$. No positioning devices were employed for the same reasons already explained.

None of the specimens underwent retrograde obturation in the apicectomized area.

\section{-Characteristics of the samples}

All samples were cleaned under a nitrogen jet and then dried in a dehydrator at a temperature of $45^{\circ} \mathrm{C}$ for 2 weeks. After the drying process, the surfaces of the specimens were metalized with a fine film of gold using a sputtering technique, allowing the biological tissues to conduct electricity.

-Scanning electron microscopy (SEM)

SEM images of the apicectomized surfaces of the root apices were taken using a Philips XL 30 (Fei Company - Eindhoven, Netherlands), showing the surface and the dentin/obturation material interface (marginal fit). An 
electron beam with energy of $20 \mathrm{keV}$ and a 4.9 spot was used. Images were taken in spread electron mode (SE). The assessment of flaws between the dentin/obturation material and the uneven apicectomized surfaces was performed using SEM images by a well trained, calibrated professional under the supervision of the professor/researcher, who is highly experienced in SEM.

-Energy dispersive spectroscopy (EDS)

The apicectomy procedures used here cause structural changes to the dentin. The reason for producing EDS analysis spectra of the chemical elements present in the dentin surfaces that were cut using these techniques is to establish parallels between the quantitative changes to the elements and the ablative technique employed.

Each group underwent analysis of the chemical composition of the apicectomized surfaces of the tooth apices using EDS. A solid state $\mathrm{Si}(\mathrm{Li})$ detector built into the electronic microscope was used for analysis, employing the same parameters used to obtain the images. Each analysis was run for 11 seconds.

-Statistical analysis

The Shapiro-Wilk test was applied to the percentages of each chemical element, verifying the normality of the distribution of the percentages. Having verified normality, the ANOVA test was applied (Tukey/Games-Howell) for homogenous and non-homogenous variables. Statistical tests were performed using SPSS ${ }^{\circledR} 11.5$ (Statistical Package for the Social Sciences, SPSS Inc., Chicago, USA), and BioEstat ${ }^{\circledR} 5.0$ software (Universidade Federal do Pará, Belém, Brazil). Statistical significance was defined at $<5 \%$.

\section{Results}

-Morphological evaluation of apicectomized surfaces

It was possible to observe by means of SEM analysis (Fig. 1) that the surfaces of group B specimens exhibited the greatest irregularity of the three groups, and were extremely carbonized and irregular (Fig. 1B).

This group also had the greatest degree of marginal fit failure, exhibiting the largest fissures between the dentin and the obturation material (Fig. 1E), when compared with groups $\mathrm{A}$ and $\mathrm{C}$ (Figs. 1D, 1F). The surfaces of group A specimens (Figs. 1A, 1D) exhibited the lowest degree both of alterations and of failures at the dentin/ obturation material interface, when compared with the other groups.

-Chemical composition of the apicectomized surfaces According to the Shapiro-Wilk test, the percentages of the chemical elements carbon, oxygen and phosphorous exhibited a normal probability distribution $(\mathrm{p}>0.05)$, whereas the percentages of calcium did not follow a normal distribution $(\mathrm{p} \leq 0.05)$.

Analysis of variance of the carbon percentages of groups $\mathrm{A}, \mathrm{B}$ and $\mathrm{C}$ demonstrated that the variance was not homogenous across the groups $(\mathrm{p}<0.05)$. Using the Games-Howell multiple comparisons test, statistically significant differences were detected when groups A and $\mathrm{B}$ and groups $\mathrm{A}$ and $\mathrm{C}$ were compared $(\mathrm{p} \leq 0.05)$. Analysis of variance of the oxygen and phosphorous percentages of groups A, B and C specimens demonstrated that the variance was homogenous across groups $(\mathrm{p}<0.05)$. The Tukey multiple comparisons test detected statistically significant differences when groups A
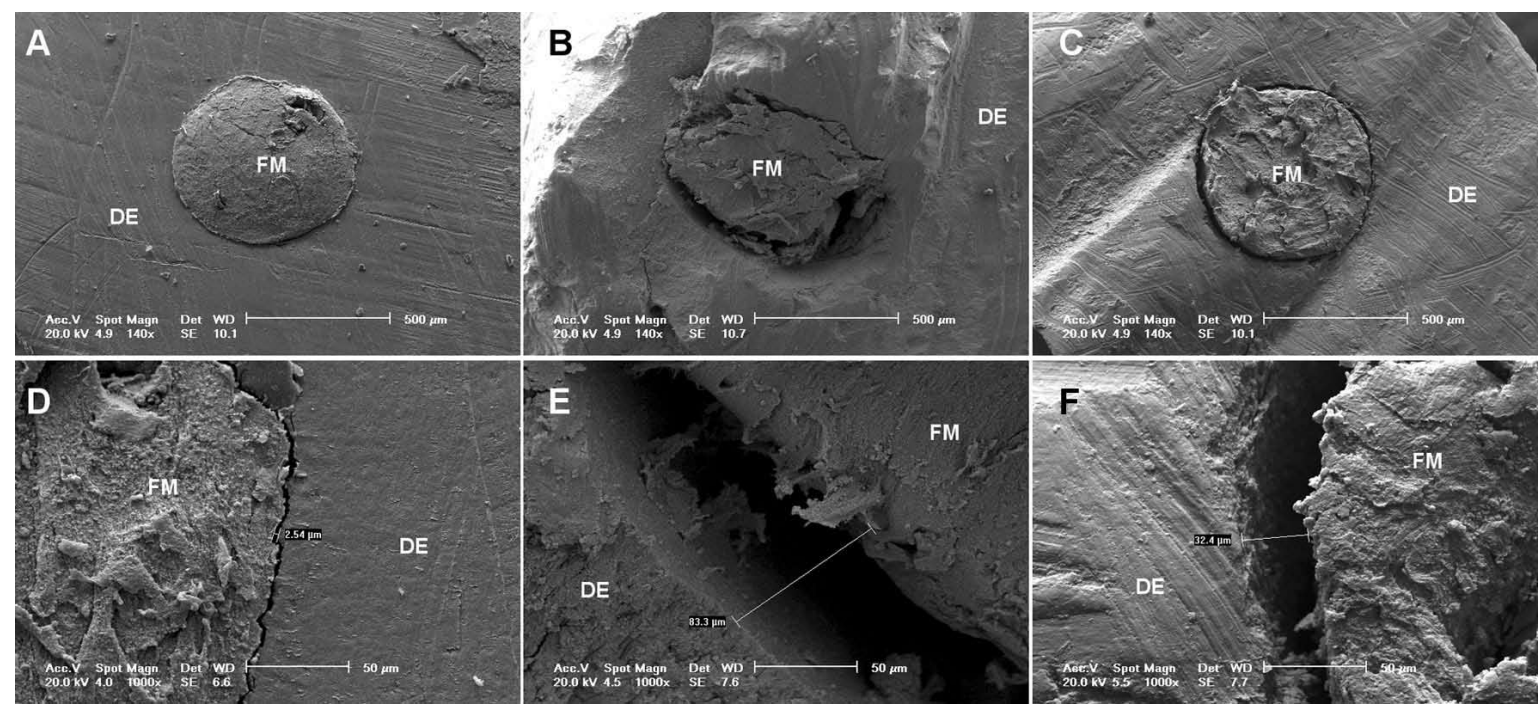

Fig. 1. Microscope images (electronic micrographs) (A, B, C, D, E and F). A) apicectomized surface from group A; B) apicectomized surface from group B, and C) apicectomized surface from group C. Magnification of 140x. D) dentin/obturation material interface from group A; E) dentin/obturation material interface from group B, and F) dentin/obturation material interface from group C. Magnification of 1000x. DE - dentin; FM - filling material. 


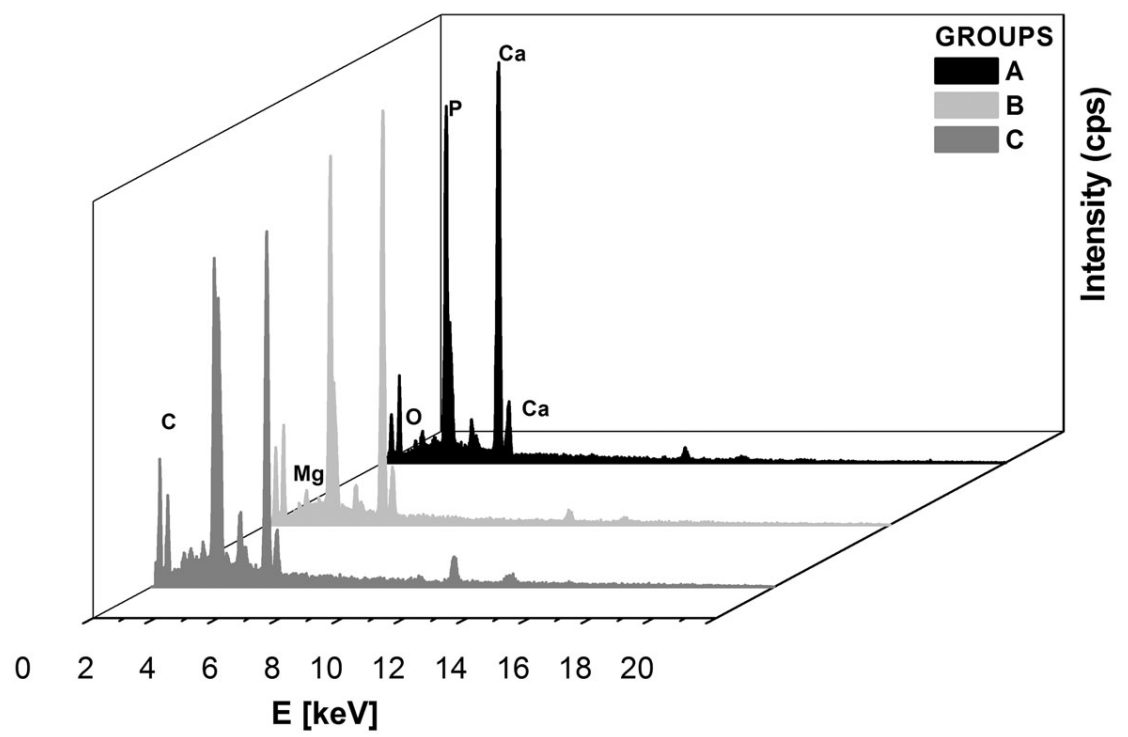

Fig. 2. Energy dispersive spectroscopy spectra for experimental groups A, B and C, illustrating the intensity of the chemical elements (y-axis), according to energy in $\mathrm{keV}$ (x-axis). $\mathrm{C}$ - carbon; $\mathrm{O}$ - oxygen; $\mathrm{Mg}$ - magnesium; $\mathrm{P}$ - phosphorous and $\mathrm{Ca}$ - calcium.

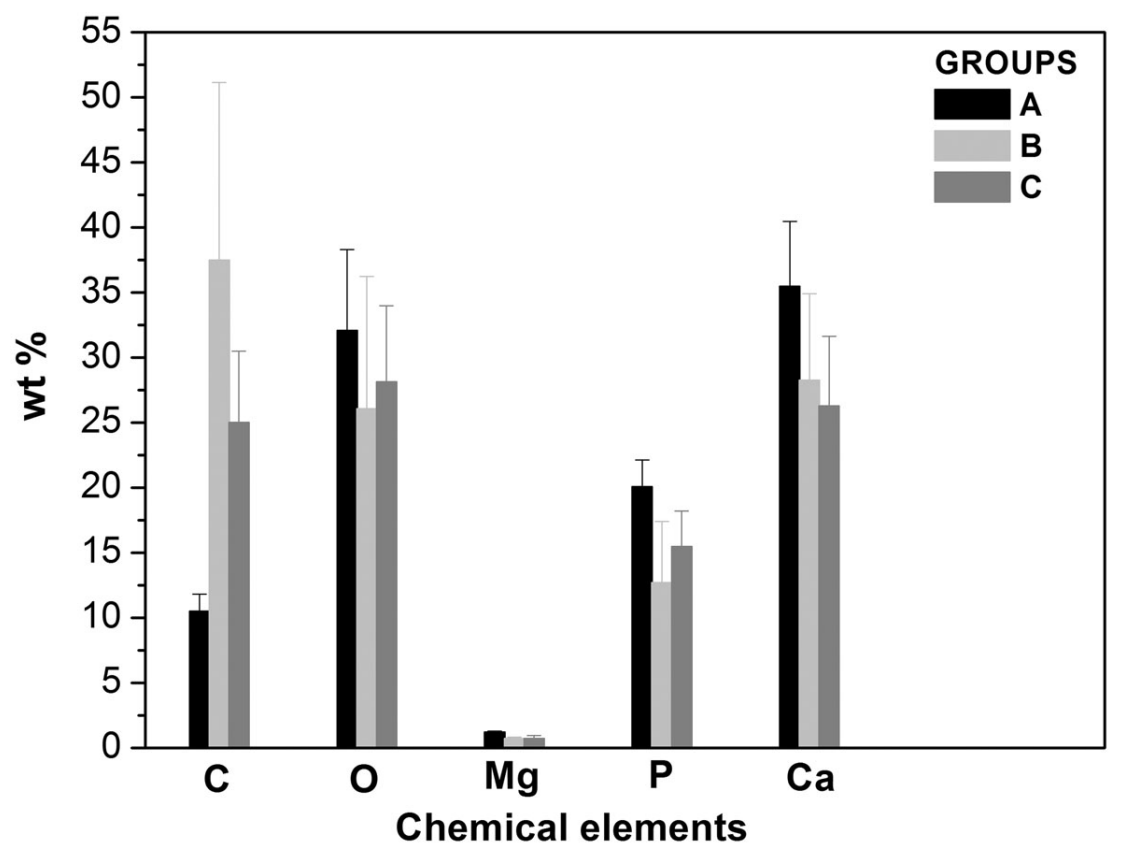

Fig. 3. Bar graph representing the distribution of the mean percentage of each chemical element (yaxis), by experimental group (x-axis). $\mathrm{C}$ - carbon; $\mathrm{O}$ - oxygen; $\mathrm{Mg}$ - magnesium; $\mathrm{P}$ - phosphorous and $\mathrm{Ca}-$ calcium. 
Table 1. Chemical elements present in apicectomized surfaces as quantified by EDS, broken down by ablation technique.

\begin{tabular}{|c|c|c|c|}
\hline \multirow[b]{3}{*}{ Chemical Elements } & \multirow{2}{*}{\multicolumn{3}{|c|}{$\begin{array}{c}\text { Percentage in weight (wt \%) } \\
\text { Mean } \pm \text { SD }\end{array}$}} \\
\hline & & & \\
\hline & Group A & Group B & Group C \\
\hline $\mathrm{C}$ & $10.48 \pm 1.34$ & $37.47 \pm 13.67$ & $24.99 \pm 5.50$ \\
\hline $\mathrm{O}$ & $32.07 \pm 6.24$ & $26.06 \pm 10.17$ & $28.13 \pm 5.86$ \\
\hline $\mathrm{P}$ & $20.05 \pm 2.09$ & $12.67 \pm 4.75$ & $15.46 \pm 2.74$ \\
\hline $\mathrm{Ca}$ & $35.46 \pm 5.00$ & $28.24 \pm 6.67$ & $26.28 \pm 5.37$ \\
\hline
\end{tabular}

and $\mathrm{B}$ and groups $\mathrm{A}$ and $\mathrm{C}$ were compared $(\mathrm{p} \leq 0.05)$. Analysis of the EDS spectra for the three groups (Fig. 2) revealed that the chemical composition of group B contained the greatest proportion of carbon, followed by group $\mathrm{C}$ and then group A. Group A exhibited a higher oxygen content than group B. Group A had a higher quantity of phosphorous than groups B and $\mathrm{C}$.

Table 1 lists the mean percentages of each chemical element according to the EDS spectra for each ablation technique. To aid with interpretation of the results, a bar chart was plotted of the mean percentages of each chemical element by experimental group (Fig. 3).

\section{Discussion}

The greater carbonization of dentin surfaces cut with the $\mathrm{CO}_{2}$ laser may be due to the fact that no cooling was applied, thus reducing its efficacy (10). The cooling systems used with the burs and with the Er:YAG laser may have resulted in an accentuated reduction in burning of the surfaces being cut $(1,2,5,10)$.

Hydroxyapatite absorbs $\mathrm{CO}_{2}$ laser radiation better than water does. This absorption transforms the light energy into heat, raising the temperature to over $700{ }^{\circ} \mathrm{C}$, which is sufficient to melt hydroxyapatite. Solidification and recrystallization of these areas, however, is almost always incomplete and noncontiguous. In contrast, Er:YAG laser light is better absorbed by water, which evaporates before the hydroxyapatite melts. This type of laser requires lower temperatures to ablate hard tissues, resulting in less thermal damage to these structures. These mechanisms, called photothermal vaporization in the case of the $\mathrm{CO}_{2}$ laser and photomechanical ablation in the case of the Er:YAG laser, probably contribute to the creation of different surfaces after irradiation (5,11-13).
The apices removed with Er:YAG exhibited more irregular surfaces when compared with those cut with burs, with compact waves with mildly elevated edges. This is due to the fact that the Er:YAG laser was used in pulsed mode, cutting the dentin in a continuously interrupted manner, and also due to movement of the specimen during exposure to radiation $(1,5,14)$.

Surfaces cut with burs were the smoothest and so exhibited the greatest dentin permeability, followed by those cut with the Er:YAG and $\mathrm{CO}_{2}$ lasers. The latter resulted in the least dentin permeability as a result of the melting and recrystallization of the dentin, obliterating dentin tubules (9).

With relation to the presence of failures at the interface between the dentin and the obturation material, the bur group had the lowest incidence and the smallest size failures, resulting in flatter surfaces and less gutta-percha displacement when compared with the other groups.

Excessive heat contributed to a worse fit of the guttapercha in apicectomies. This may explain why the $\mathrm{CO}_{2}$ laser group exhibited the greatest degree of marginal infiltration, since this laser was used without cooling (15-17).

There was a tendency for carbonates and phosphates to reduce after irradiation with both types of laser, which supports the suspicion that mineral components suffer ablation during the process. There were also reductions in the quantities of calcium and phosphorous. Irradiation with the Er:YAG laser provoked greater losses of proteins and water than of carbonates and phosphates from dental hard tissues (5). The results of this research demonstrated lower quantities of phosphorous in the laser groups when compared with the bur group.

The differences between the bur and $\mathrm{CO}_{2}$ laser groups for the element oxygen demonstrate greater quantities 
in the bur group, which can be attributed to the intense burning the dentin structure suffered under $\mathrm{CO}_{2}$ laser radiation, leading to intense water losses in the process.

Based on the tissue ablation methodologies employed and on the analysis of the data obtained, it has been possible to draw the following conclusions:

- specimens apicectomized with burs exhibited less dentin surface irregularities than the laser groups;

- the $\mathrm{CO}_{2}$ laser group exhibited the greatest degree of marginal fit failure, with larger fissures between dentin and obturation material when compared with the other groups;

- specimens in the $\mathrm{CO}_{2}$ laser group exhibited the greatest quantity of the element carbon when compared with the other groups, as a result of the laser-related carbonization observed on the apicectomized surfaces of the samples evaluated in this study.

\section{References}

References with links to Crossref - DOI

1. Paghdiwala AF. Root resection of endodontically treated teeth by erbium: YAG laser radiation. J Endod. 1993;19:91-4.

2. De Mello ED, Pagnoncelli RM, Munin E, Filho MS, De Mello GP, Arisawa EA, et al. Comparative histological analysis of bone healing of standardized bone defects performed with the Er:YAG laser and steel burs. Lasers Med Sci. 2008;23:253-60.

3. Abad-Gallegos M, Arnabat-Domínguez J, España-Tost A, BeriniAytés L, Gay-Escoda C. In vitro evaluation of the temperature increment at the external root surface after Er,Cr:YSGG laser irradiation of the root canal. Med Oral Patol Oral Cir Bucal. 2009;14:e658-62.

4. Arens DL, Levy GC, Rizoiu IM. A comparison of dentin permeability after bur and laser apicoectomies. Compendium. 1993;14:1290,1292,1294.

5. Sasaki KM, Aoki A, Masuno H, Ichinose S, Yamada S, Ishikawa I. Compositional analysis of root cementum and dentin after Er:YAG laser irradiation compared with $\mathrm{CO} 2$ lased and intact roots using Fourier transformed infrared spectroscopy. J Periodontal Res. 2002;37:50-9.

6. Araki AT, Ibraki Y, Kawakami T, Lage-Marques JL. Er:Yag laser irradiation of the microbiological apical biofilm. Braz Dent J. 2006;17:296-9.

7. Moritz A, Gutknecht N, Goharkhay K, Schoop U, Wernisch J, Pöhn C, et al. Then carbon dioxide laser as an aid in apicoectomy: an in vitro study. J Clin Laser Med Surg. 1997;15:185-8.

8. Miserendino LJ. The laser apicoectomy: endodontic application of the $\mathrm{CO} 2$ laser for periapical surgery. Oral Surg Oral Med Oral Pathol. 1988;66:615-9.

9. Gouw-Soares S, Stabholz A, Lage-Marques JL, Zezell DM, Groth EB, Eduardo CP. Comparative study of dentine permeability after apicectomy and surface treatment with 9.6 microm TEA CO2 and Er:YAG laser irradiation. J Clin Laser Med Surg. 2004;22:129-39.

10. Sasaki KM, Aoki A, Ichinose S, Ishikawa I. Morphological analysis of cementum and root dentin after Er:YAG laser irradiation. Lasers Surg Med. 2002;31:79-85.

11. Keller U, Hibst R. Experimental studies of the application of the Er:YAG laser on dental hard substances: II. Light microscopic and SEM investigations. Lasers Surg Med. 1989;9:345-51.

12. Moritz A, Schoop U, Goharkhay K, Jakolitsch S, Kluger W, Wernisch J, et al. The bactericidal effect of Nd:YAG, Ho:YAG, and Er:YAG laser irradiation in the root canal: an in vitro comparison. $\mathrm{J}$ Clin Laser Med Surg. 1999;17:161-4.

13. Sasaki KM, Aoki A, Ichinose S, Ishikawa I. Ultrastructural analysis of bone tissue irradiated by Er:YAG Laser. Lasers Surg Med. 2002;31:322-32.
14. Hibst R, Keller U. Experimental studies of the application of the Er:YAG laser on dental hard substances: I. Measurement of the ablation rate. Lasers Surg Med. 1989;9:338-44.

15. Cunningham J. The seal of root fillings at apicectomy. A scanning electron microscope study. Br Dent J. 1975;139:430-5.

16. Lin LM, Pascon EA, Skribner J, Gängler P, Langeland K. Clinical, radiographic, and histologic study of endodontic treatment failures. Oral Surg Oral Med Oral Pathol. 1991;71:603-11.

17. Weston GD, Moule AJ, Bartold PM. A scanning electron microscopic evaluation of root surfaces and the gutta-percha interface following root-end resection in vitro. Int Endod J. 1999;32:450-8.

\section{Acknowledgments}

This research was funded by CAPES, Brazil, and has been approved by the Research Ethics Committee at the Pontifícia Universidade Católica do Rio Grande do Sul, protocol number 1061/05. 